\title{
小麦ライ來間の $\mathrm{F}_{1}$ 種子に対するコルヒチン処理時
}

\section{に於ける溫度及び濃度に就て}

\author{
山 本 喜 良 (楿農科大学)
}

On the temperature and the concentration of colchicine solution in treating the Triticum vulgare $\times$ Secale cereale $F_{1}$ seeds.

Kiyoshi Yamamoro (Kagawa College of Agriculture)

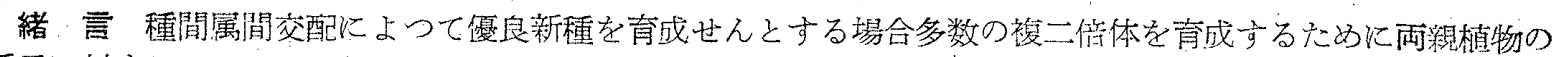
種子に対寸るコルヒチン好理は一つの有効な方法である。篗者は小麦メライ麦の $F_{1}$ 稙子に対する適当なコル ヒチン処理法を明かにするためコルヒチンの濃度交び処理特の温度に関して実験を行つた。

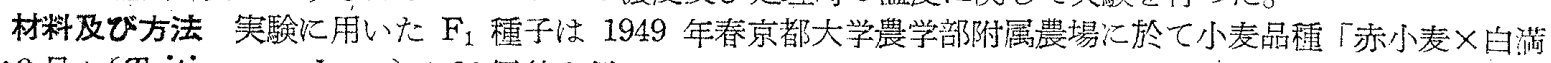
作了是」(Triticum vulgare) の31個体を囲としラ 了麦「Petkuser」(Secale cereale) の9個体を父々 して得たもので女る。処理液の濃度は $0.05 \%$ 支び $0.025 \%$, 温度惊高温 $25^{\circ} \mathrm{C}$, 窑温 $11 \sim 17^{\circ} \mathrm{C}$, 低温 $4 \sim 6$ ${ }^{\circ} \mathrm{C}$ 乙 条件を組合せて6 試験区を作つた。別に標準区とし てコルヒチン液の代りに水に種子を入れて等温に保 つ应を設けた。各区に $F_{1}$ 種子を分配する場合，或 る新個体より採つた種子方゙或る区にの多偏らずなる ベく全個体の種子が各区に平均与る様に留意した。

1949 年 10 月 26 日シャーレ中の湿つた漑䋊上

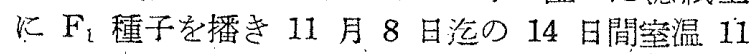
ー $17^{\circ} \mathrm{C}$ で発芽させた。コルヒチン好理は 10 月 30 日より開始した。幼芽梢が約 $1 \mathrm{~cm}$ になると幼第の 成長点を㑺け㨾にして其の先端を切り離し成長点 ヘのコルヒチンの漫入を容易ならしめた。コルヒチ ン処理時間は 24 時間と乙処理後約 2 時間水洗し予 めフォルマンで消琵した播種箱の土敖に移植し爾後 ガラス符置いて育成した。11月14日より1月 15 日过に 4 回の外觀調查と检鏡による気孔調㚗と をなし更に生存個体に就て 1950 年 6 月稳性の調盉 字実施した。

気轧の大さは一般に葉位攻び葉中の場所によつて 変化する(中村迎 1943 その他) $)^{1}$ が本実験では約 5 －10 cm の本葉3枚目の中央部鼠面の表皮を剝ぎと り梌镜に供した。佮気孔の大さは接眼微尺度子用い Karnew $4 \times 7$ にて長径，矩径を測定し其の積を以 て表した。一方無処理区及び本実虑の両睍と同じ品 種和ら既に京大育種学研究室で作られている複二倍 体の一系統217-1-3 就てその気孔を同様の方法 で測定し認定の基淮に用いた。斯くして第一表に示 寸処理個体a の如き気孔の大さを示す個体は此を非

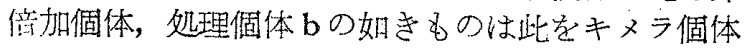

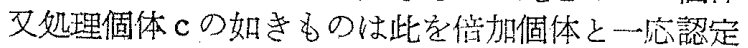
した。倚処理個体が成熟した後生存せる全個体に就 て稔性調查を行い染色体の倬加によりて起るべき稔 泩と気孔の大さ汇よる倍加の判定との関係を考察し

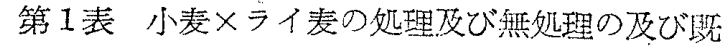
成複二倍体の気孔の大さ

(単位は Karnew $4 \times 7$ 接眼微尺洨目にて測)

\begin{tabular}{|c|c|c|c|c|c|}
\hline $\begin{array}{l}\text { 気 } \\
\text { 孔 } \\
\text { の } \\
\text { 大 } \\
\text { さ }\end{array}$ & $\begin{array}{l}\text { 無 } \\
\text { 始 } \\
\text { 理 } \\
F_{1}\end{array}$ & $\begin{array}{l}\text { 既二 } \\
\text { 战倍 } \\
\text { 複体 }\end{array}$ & 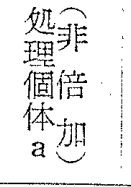 & $\begin{array}{l}\text { 㚭 } \\
\text { 理 } \\
\text { 個メ } \\
\text { 体亏 } \\
\mathrm{b} \smile\end{array}$ & $\begin{array}{l}\text { 㜆烃 } \\
\text { 理 } \\
\text { 個. } \\
\text { 体加 } \\
\text { c }\end{array}$ \\
\hline $\begin{array}{l}250 \\
270 \\
290 \\
310 \\
330\end{array}$ & $\begin{array}{r}3 \\
13 \\
19 \\
43\end{array}$ & * & $\begin{array}{l}4 \\
2 \\
8\end{array}$ & $\begin{array}{l}1 \\
1 \\
1\end{array}$ & \\
\hline $\begin{array}{l}350 \\
370 \\
390 \\
410 \\
430\end{array}$ & $\begin{array}{r}26 \\
34 \\
11 \\
7 \\
1\end{array}$ & $\begin{array}{l}1 \\
2\end{array}$ & $\begin{array}{r}6 \\
10 \\
4 \\
4 \\
1\end{array}$ & $\begin{array}{l}1 \\
4 \\
1 \\
2 \\
2\end{array}$ & $\begin{array}{l}1 \\
1\end{array}$ \\
\hline $\begin{array}{l}450 \\
470 \\
490 \\
510 \\
530\end{array}$ & $\begin{array}{l}1 \\
2\end{array}$ & $\begin{array}{r}2 \\
9 \\
5 \\
10 \\
18\end{array}$ & 1 & $\begin{array}{l}2 \\
1 \\
3 \\
1 \\
5\end{array}$ & $\begin{array}{l}1 \\
1 \\
2 \\
1 \\
4\end{array}$ \\
\hline $\begin{array}{l}550 \\
570 \\
590 \\
610 \\
630\end{array}$ & $y$ & $\begin{array}{l}17 \\
19 \\
21 \\
16 \\
18\end{array}$ & 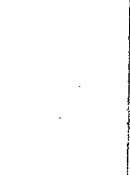 & $\begin{array}{l}3 \\
1 \\
2 \\
1\end{array}$ & $\begin{array}{l}1 \\
4 \\
6 \\
4 \\
1\end{array}$ \\
\hline $\begin{array}{l}650 \\
670 \\
690 \\
710 \\
730\end{array}$ & & $\begin{array}{l}8 \\
8 \\
1 \\
1\end{array}$ & & $\begin{array}{l}1 \\
4 \\
1 \\
1\end{array}$ & 2 \\
\hline $\begin{array}{l}750 \\
770 \\
790 \\
810\end{array}$ & & $\begin{array}{l}1 \\
1 \\
2\end{array}$ & & 1 & \\
\hline$\overline{\bar{t}} \overline{\mathrm{A}}$ & 160 & 160 & 30 & 40 & 30 \\
\hline $\mathrm{M} \pm \mathrm{PE}$ & $\begin{array}{l}43.8 \\
\pm 1.98 \\
\end{array}$ & $\begin{array}{l}56.2 \\
\pm 3.56 \\
\end{array}$ & $\begin{array}{r}343.4 \\
\pm 5.75 \\
\end{array}$ & $\begin{array}{l}500.0 \\
\pm 13.52 \\
\end{array}$ & $\begin{array}{l}49.4 \\
\pm 8.21 \\
\end{array}$ \\
\hline
\end{tabular}

* 昭和 25 年 9 月 22 日 第 88 回講演会に於て発表

日本作物学会紀事 第 21 巻 第 3 4 号 
た。此の際各個体全穂を調查した。稔実個体は 1 粒より90 粒沦着粒し且稔実穗数も 1 5 穂の変異があつた が少数の粒でも㦈粒せる個体を稔奏個体とし一粒も結実しないるのを不稔笑個体として区分した。䏌稔性調梖 は岡克氏を暊わして行つたものである。

実験結果及び考察 コルヒチン观理を行つた幼植物の外形及びその気孔の大されより非倍加個体，キメラ個 体及び倍加個体に分類した結果は第二表の如くである。

第 2 表 コルヒチン処理を行つた幼植物の外形並びに 気孔の大さによる倍加及文び非倍加の検定

1) 笑数 2) 供試 $\mathrm{F}_{1}$ 個体数に刘する\%

\begin{tabular}{|c|c|c|c|c|c|c|c|c|}
\hline \multirow{2}{*}{ 就 } & \multirow{2}{*}{ 区 } & \multirow{2}{*}{$\begin{array}{l}\text { 低試 } F_{1} \\
\text { 個体数 }\end{array}$} & 外 & & \multicolumn{3}{|c|}{$\begin{array}{l}\text { 気孔の大さ } \\
\text { による分 }\end{array}$} \\
\hline & & & $\begin{array}{l}\text { 正 常 } \\
\text { 值 }\end{array}$ & $\begin{array}{l}\text { 肥檿 } \\
\text { 個体 }\end{array}$ & $\begin{array}{l}\text { 枯㱜 } \\
\text { 個体 }\end{array}$ & $\begin{array}{l}\text { 韭倍加 } \\
\text { 個 体 }\end{array}$ & $\begin{array}{l}* \times \bar{y} \\
\text { 個 体 }\end{array}$ & $\begin{array}{l}\text { 售加 } \\
\text { 個体 }\end{array}$ \\
\hline 高：混 & $0.025 \%$ & 81 & $\begin{array}{l}12^{1)} \\
14.81^{27}\end{array}$ & $\begin{array}{c}23 \\
28.39 \\
\end{array}$ & $\begin{array}{c}46 \\
56.79 \\
\end{array}$ & $\begin{array}{c}14 \\
17.28\end{array}$ & $\begin{array}{c}12 \\
14.81\end{array}$ & $\frac{9}{11.11}$ \\
\hline $25^{\circ} \mathrm{C}$ & $0.05 \%$ & 91 & $\begin{array}{l}1 \\
1.09 \\
\end{array}$ & $\begin{array}{c}6 \\
9.59 \\
\end{array}$ & $\begin{array}{c}84 \\
92.30 \\
\end{array}$ & $\begin{array}{l}0 \\
0\end{array}$ & $\begin{array}{c}4 \\
4.39 \\
\end{array}$ & $\begin{array}{c}3 \\
3.29 \\
\end{array}$ \\
\hline 空 温 & 0.0 & 70 & $\begin{array}{c}17 \\
24.28 \\
\end{array}$ & $\begin{array}{c}20 \\
28.57 \\
\end{array}$ & $\begin{array}{c}33 \\
47.14 \\
\end{array}$ & $\begin{array}{c}14 \\
20.00\end{array}$ & $\begin{array}{c}15 \\
21.42\end{array}$ & $\begin{array}{c}8 \\
11.42 \\
\end{array}$ \\
\hline $11-17$ & $0.05 \%$ & 92 & $\begin{array}{c}10 \\
10.86 \\
\end{array}$ & $\begin{array}{c}20 \\
14.13\end{array}$ & $\begin{array}{c}66 \\
75.00\end{array}$ & $\begin{array}{c}14 \\
11.95\end{array}$ & $\begin{array}{c}4 \\
4.34\end{array}$ & $\begin{array}{l}8 \\
8.99\end{array}$ \\
\hline 低 温 & $0.025 \%$ & 89 & $\begin{array}{c}15 \\
16.85\end{array}$ & $\begin{array}{c}35 \\
39.32\end{array}$ & $\begin{array}{c}39 \\
43.82\end{array}$ & $\begin{array}{c}12 \\
13.48\end{array}$ & $\begin{array}{c}23 \\
25.84\end{array}$ & $\begin{array}{c}15 \\
16.85\end{array}$ \\
\hline $4 \sim 6^{\circ} \mathrm{C}$ & $5 \%$ & 76 & 5.26 & $\begin{array}{c}36 \\
47.36 \\
\end{array}$ & $\begin{array}{c}36 \\
47.36 \\
\end{array}$ & $\begin{array}{c}6 \\
7.89\end{array}$ & $\begin{array}{c}8 \\
10.52\end{array}$ & $\begin{array}{c}26 \\
34.21 \\
\end{array}$ \\
\hline 標 & $区$ & 31 & $\begin{array}{l}31 \\
100 \\
\end{array}$ & $\begin{array}{l}0 \\
0 \\
\end{array}$ & $\begin{array}{l}0 \\
0 \\
\end{array}$ & $\begin{array}{r}31 \\
100 \\
\end{array}$ & $\begin{array}{l}0 \\
0\end{array}$ & $\begin{array}{l}0 \\
0 \\
\end{array}$ \\
\hline
\end{tabular}

先づ外形を見ると正常個体の出現 率は高温の高濃度区は極めて少く約 1\%であり，特に多いのは窒温の低 濃度区で $20 \%$ 以上に选するが其の 他の区では約5-17\%であり各温庤 共浱度が大となると出現率は少くな つていた。一力肥厚型ば高温の高溽 度区は少ぐ約7\%であり，多いのは 低温区で低浱度，高浱度区はそれぞ れ約 39 及る゙ $47 \%$ で其の他の区は 中間の約 $14-29 \%$ の範囲に专つ た。枯死率は低温区及び公温の低濃 度区では慨して低く約 44-47\% で あつたのに反し高温の高濃度区は約 92\%に達し，他の区は其の!間で約 57一75\%であつた。

次に気孔の大さによる区分を見る 之非倍加個体の\%恪温度共高濃安 区怟濃度区よりも少く特て高温の高濃度区では0であつた。キャラ個体の\%は高温及び室温兩区の高濃度区

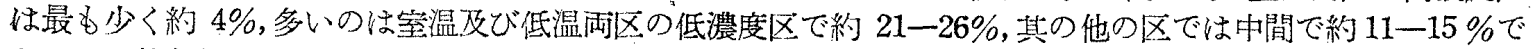
あつた。偣加個体の\%は高温の高濃度区は少く約 3\%，多いのは低温の高浱度区の約 $34 \%$ で他の区は約 917\%で守間であつた。以上の姑く高混及び室温では倍加個体及びキャラ個体の共に高濃度区は低濃度区よりる 低いが低温ではキメラ個体の\%は低濃度区が多く倍加個体の\%は其の逆になつていた。又等温及び低温の高襄 度区は倍加個体の\%はキヌラのそれさり多多かつた。此れは室温及び低温に於て稀薄な場合はキャラで停るも のが液が浱くなればより念い部分に倍加現鼠を起寸結果でないかと考えられる。又高温の高濃度区では枯死個

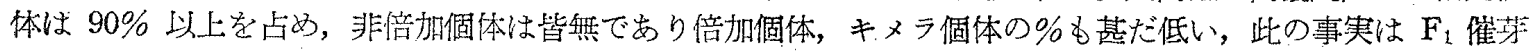
種子刘するコルヒチンの害作用が高温に於て強調された事を示すものである。而して外形と気孔の大さによ る区分との関係を見ると正常個体の\%灭び非倍加個体の\%の大小の順序は大体一致し各区間に於故る耐者の\% の差は比䡆的少い。恐らく外形正常な個体の大部分が非倍加個体であり肥厚個体の大部分がキメラ及び偣加倨 佮になつたものとなし得よう。

幼植物の肥厚状態並びに気孔の大さのみでは真の倍加についての決定はなし得ないので更に生存個体の稔性

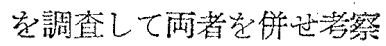
した。其の結果以第三表に 示す如くである。一般に小 渗 $\times$ ライ麦の $\mathrm{F}_{1}$ 植物は

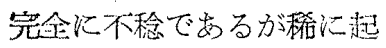
る染色体の倍加によつて稳 程が生する（FLORELI 193 6) $)^{2}$ 。故に $F_{1}$ 植物の穃些 注染色体の倍加を推定せ乙

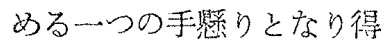
よう。第三菱炕って示さ れる如く稔実個体は気孔の 夫さによつて一珫証定した 留加及びキメラ個体中心多 く見られ非倍加之㒛定した ものでは極めて少なかり 第1表 幼植物の気孔による倍加，非倍加の検定と稔性との関係



た。文キャラ個体と認定したものの中に稔実個体が相当少いことは植物体の成長に伴つて倍加組織が生殖細胞

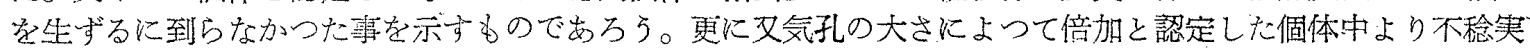

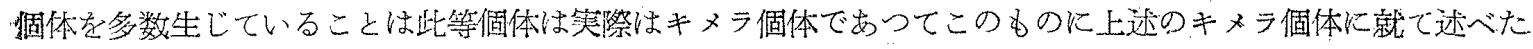


ものと同槉のことが起つたものと言えよう。而して供試個体数に対する稔奏個体の\%を各区間で比較すると高

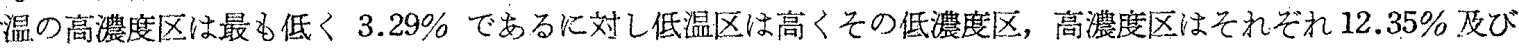
$13.16 \%$ であり高濃度区に於て多少高い值を示すが大差がない。其の他の区は中間で約 6一9\% の範囲にあつ た。上上の如く小麦メライ麦の $\mathrm{F}_{1}$ 催芽種子に対してコルヒチン処理を行う場合本実駼の範团では低温が最も よい。濃度は $0.025 \%$ より $0.05 \%$ がより效果的である様であるが其の間に大差はない。

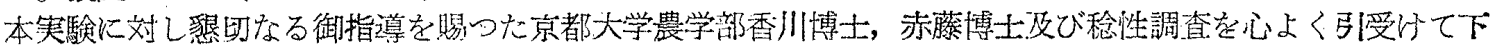
さつた岡克氏に対し深甚なる謝意を表す。

摘 要 (1) 小友×ライ考の催芽種子を複二倍体にするためのコルヒチン処理に於て好適の温度及びコル

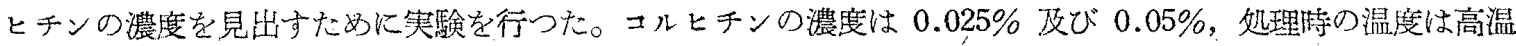

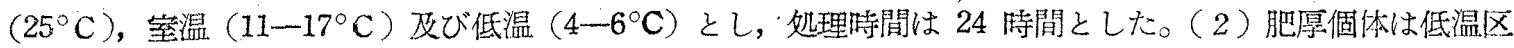
飞多く䟴度により約 40-47\%，その他の区は約 7一29\%で女つた。枯死個体は高温及び堂温の 0.05\%区に多

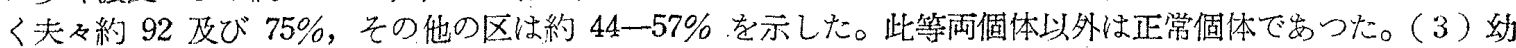
植物の気孔の大さで染色体の倍加を検定した。非倍加個体は区により0-20\%で外形正常個体の\%と胳了刘庶 している。キメラ個体は室温及び低温の $0.025 \%$ 区で大なる值を示し夫々約 $21 \%$ 支び $26 \%$ ，その他の区は 約 4-15\%であつた。偣加個体は低温の $0.05 \%$ 区は最大で約 34\% に達し，其の他の区は約 3-17\% を示 乙た。（4）成熟植物の悡性によつて染色体の倍加を椧定した。稔実個体数は谷孔の大さによつて推定したキ メラ皮ざ倍加個体数より可なり減少したが稔実個体の大部分がキメラ及び倍加個体と䜀定した。稳实個体は高 温の $0.05 \%$ 区は最も少く約 $3 \%$ であつたが低温では大であり $0.025 \%$ 区は約 $12 \%$ ０.05\%区は約 $13 \%$ で

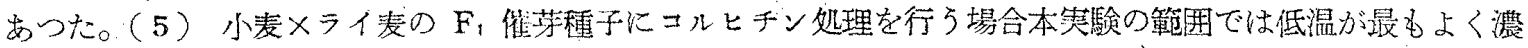
度は $0.025 \%$ 区之 $0.05 \%$ 区とは路? 同様の効果学示す。

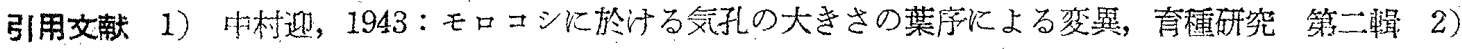
Floreli, V. H. 1936 : Chromosome differences in a wheat-rye amphidiploid Iour. Agr. Res., 52. No. 3 .

\section{Réusmé}

1. Studies were made to find the favourable temperatures and concentrations of colchicine solution to induce amphidiploid in germinating seeds of Triticum vulgare $\times$ Secale cercale $\mathrm{F}_{1}$. The concentrations tested were $0.025 \%$ and $0.05 \%$, and the temperatures were high $\left(25^{\circ} \mathrm{C}\right)$, medium $\left(11 \sim 17^{\circ} \mathrm{C}\right)$ and low $\left(4 \sim 6^{\circ} \mathrm{C}\right)$. The treatments were carried for $24 \mathrm{hrs}$.

2. The percentage of swelled plants was high at low temperatures, being $\mathrm{Ca}$. 40 in 0.025 $\%$ solution and $\mathrm{Ca} .47$ in $0.05 \%$, while it was $\mathrm{Ca} .7 \sim 29$ in the other plots. The percentage of plants which died was high in the $0.05 \%$ solution of high and medium temperatures, being $\mathrm{Ca} .92$ and 75 respectively, while, it was $\mathrm{Ca} .44 \sim 57$ in other plots. The plants other than those above mentioned grew normally.

3. By the size of stomata in young plants, the chromosome doubling was tentatively judged. The percentage of plants in which the chromosomes have not been doubled was $0 \sim 20$, corresponding nearly to that of normal plants judged by external appearence. The percentge of chimera as was high in $0.025 \%$ solution at medium and low temperatures, being $\mathrm{Ca} .21$ and 26 respectively, while it was $\mathrm{Ca} .4-15$ in other plots. The percentage of plants classified as those in which the chromosome doubling was widely occurred was the highest, $\mathrm{Ca}$. 34, in the $0.05 \%$ solution of low temperature while it was $\mathrm{Ca}$. $3 \sim 17$ in the other plots.

4. By the fertility of matured plants, the chromosomal doubing was checked. The number of plants which set grains was found smaller than that of chimeras and the plants in which the doubling was assumed to have widely occurred from the stomatal size. Most of the plants setting grains, however, were found among those that were classified as chimeras and the plants in which the doubling was widely occurred. The percentage of plants setting grains was the poorest, $\mathrm{Ca}$. 3 , in $0.05 \%$ solutions of high temperature, while at low temperatures it was $\mathrm{Ca} .12$ in $0.025 \%$ and $\mathrm{Ca} .13$ in $0.05 \%$ solutions.

5. So far as the present experiment is concerned, the effect of colchicine on the germinating seeds of Triticum vulgare $\times$ Secale cereale $F_{1}$ was the best at low temperature, the concentrations of solution of both $0.05 \%$ and $0.025 \%$ showing almost the same result. 